\title{
Characteristics of calcaneal osteomyelitis: an unusual and severe form of diabetic foot disease
}

\author{
SHEILA M GRECIAN, PAUL J CHADWICK, SAMANTHA J HAYCOCKS, PAUL R CHADWICK, \\ ROBERT J YOUNG, ANGELA N PAISLEY
}

\begin{abstract}
Background: Osteomyelitis of the calcaneus is an uncommon type of diabetic foot infection considered to have a poor outcome. Little is known about predisposing and prognostic factors, or optimum treatment regimens.

Methods: Case records were reviewed of the eight patients with diabetes who presented to our centre during 2011-13 with calcaneal osteomyelitis and a complementary group of 19 patients who presented with heel ulcers but without osteomyelitis.

Results: Male sex (6/8 vs. 4/19; $p<0.05)$, peripheral neuropathy (8/8 vs. 4/19; $p<0.001)$, ulcer size $>2 \mathrm{~cm}^{2}$ (8/8 vs. 3/19; $\mathrm{p}<0.0001)$ and depth (probing to bone) $(6 / 8$ vs. $0 / 19$; $\mathrm{p}<0.0001)$ were associated with calcaneal osteomyelitis. We were unable to identify any patient or treatment characteristics in the osteomyelitis group that conferred improved outcome. Outcomes at 30 weeks after presentation were significantly poorer in the osteomyelitis group (ongoing osteomyelitis or amputation $4 / 8$, and death $2 / 8$ ) than in the ulcer only group (1/19 and 2/19).

Conclusions: In patients with diabetes and heel ulcers, calcaneal osteomyelitis is associated with male gender, neuropathy and large deep ulcers. It is uncommon and has a poor prognosis. We were unable to identify any factors associated with improved prognosis.

Br J Diabetes Vasc Dis 2015;15:166-168
\end{abstract}

Key words: calcaneal osteomyelitis, diabetes

\section{Introduction}

It is well known that diabetic foot infections are associated with significant morbidity and mortality ${ }^{1}$; however, optimal management of these infections improves outcomes, including reduced

Salford Royal Hospital, Manchester, UK

Address for correspondence: Sheila Grecian

c/o Dr A Paisley, Department of Diabetes and Endocrinology, Salford

Royal Hospital, Manchester, M6 8HD, UK.

Tel: +44 (0)161 2065157

E-mail: sheila.grecian@nhs.net

http://dx.doi.org/10.15277/bjdvd.2015.042 incidence of major limb amputation. ${ }^{2}$ Osteomyelitis of the calcaneus, an uncommon type of foot infection, is often considered to confer worse outcomes than cellulitis or osteomyelitis of the more distal bones and is extremely difficult to treat. ${ }^{3}$ Infection complicates ulcers caused by pressure or trauma on a background of peripheral neuropathy, vasculopathy or a combination of the two. Treatment options include antibiotics, radical debridement and major amputation. Despite calcaneal osteomyelitis in the diabetic foot being identified as a marker for poor outcome, very little has been published about specific predisposing or prognostic factors, or optimum treatment regimens.

This report describes an audit of our recent experience of such patients, prompted by the case of a patient with calcaneal osteomyelitis who progressed to a below knee amputation. We compared a series of diabetes patients with calcaneal osteomyelitis, and a complementary series of diabetes patients with heel ulcers but no osteomyelitis, in order to better understand whether there are any characteristics specifically associated with the development and outcome of calcaneal osteomyelitis.

\section{Patients and methods}

A search was performed of all patients who had attended the multidisciplinary foot clinic at Salford Royal NHS Foundation Trust between 2011 and 2013 inclusive, during which time more than 1500 diabetic patients with new ulcers were treated. Eight patients were identified as having osteomyelitis of the calcaneus confirmed by MRI, and 19 patients had heel ulcers but no clinical or radiological evidence of osteomyelitis. The case records for all 27 patients were retrospectively reviewed. All patients had been managed according to local guidance with regards to debridement, dressings, offloading and antibiotics by the multidisciplinary foot team. This analysis was undertaken in line with Trust clinical governance and audit procedures.

Demographics and diabetes history (type/duration/control/ complications) were ascertained. Ulcer characteristics including size, depth, base tissue type and evidence of surrounding cellulitis were classified. The management plan employed for each patient was recorded along with the outcome at the time of analysis. A table of all factors was created to ensure a consistent approach to the record review. The Mann-Whitney test and Fisher's exact test (two-tailed) were used to determine if there were any significant differences between the populations. 
Table 1. Characteristics of patients and foot pathology reviewed

\begin{tabular}{|c|c|c|c|}
\hline Baseline Factor & $\begin{array}{l}\text { Patients } \\
\text { with } \\
\text { osteomyelitis }\end{array}$ & $\begin{array}{l}\text { Patients } \\
\text { with no } \\
\text { osteomyelitis }\end{array}$ & $\mathbf{p}^{\mathrm{a}}$ \\
\hline Age, median (range) (y) & $78(42-86)$ & $71(45-94)$ & 0.8103 \\
\hline \multirow[t]{2}{*}{ BMI, median (range) } & $26.5(18.5-44)$ & $29(18-68)$ & 0.8414 \\
\hline & & & $p^{b}$ \\
\hline Male sex & $6 / 8$ & $4 / 19$ & 0.0248 \\
\hline Type 1 diabetes & $1 / 8$ & $5 / 17$ & 0.6334 \\
\hline Duration of diabetes $\geq 10$ years & $5 / 7$ & $14 / 17$ & 0.6080 \\
\hline $\begin{array}{l}\mathrm{HbA}_{1 \mathrm{c}}>70 \mathrm{mmol} / \mathrm{mol} \\
(8.6 \%)\end{array}$ & $2 / 7$ & $8 / 18$ & 0.6592 \\
\hline Peripheral vascular disease & $1 / 8$ & $9 / 19$ & 0.1895 \\
\hline Peripheral neuropathy & $8 / 8$ & $4 / 19$ & 0.0002 \\
\hline $\begin{array}{l}\text { Chronic kidney disease } \\
\text { stage } 4-5\end{array}$ & $4 / 8$ & $6 / 19$ & 0.6578 \\
\hline Ulcer size $\geq 2 \mathrm{~cm}^{2}$ & $8 / 8$ & $3 / 19$ & $<0.0001$ \\
\hline Ulcer depth (probe to bone) & $6 / 8$ & $0 / 19$ & $<0.0001$ \\
\hline Ulcer base necrotic/sloughy & $4 / 8$ & $6 / 19$ & 0.4147 \\
\hline Surrounding cellulitis & $3 / 8$ & $5 / 19$ & 1.0000 \\
\hline
\end{tabular}

\section{Results}

\section{Predisposing factors}

Demographic and other data are presented in Table 1. The majority of patients were elderly and had type 2 diabetes. Duration of diabetes and diabetes control (assessed by $\mathrm{HbA}_{1 \mathrm{c}}$ at time of ulcer presentation) was found to be similar in those with and without osteomyelitis. Male sex and presence of peripheral neuropathy were the only patient characteristics significantly more prevalent in the osteomyelitis group. With regard to ulcer characteristics, penetration to bone (probing to bone) and larger ulcer size were significantly associated with the presence of osteomyelitis.

\section{Factors that might influence prognosis in patients with osteomyelitis}

All patients had a plain X-ray upon presentation; only 3 of the 8 osteomyelitis patients had baseline changes. The patients with osteomyelitis who at the time of analysis were alive with ulcers that had healed were compared with those whose ulcers were persistent, in whom surgical intervention had been necessary or who had died (Table 2). None of the patient characteristics, baseline investigation results (white cell count, C-reactive protein, initial X-ray changes [3/8]) or microbial population (mixed growth in 7/8) were found to be associated with outcome.

\section{Outcome comparison between heel ulcer patients with} and without osteomyelitis

Outcomes at 30 weeks in the osteomyelitis (OM) group were worse than the ulcer only (UO) group. There was higher mortality (OM $2 / 8$ [25\%]; نO 2/19 [10.5\%]) and, among the survivors, less heal-
Table 2. Presenting characteristics of patients with calcaneal osteomyelitis and outcome at 30 weeks

\begin{tabular}{llll}
\hline Factor & $\begin{array}{l}\text { Patients } \\
\text { alive and } \\
\text { healed }\end{array}$ & $\begin{array}{l}\text { Patients } \\
\text { with } \\
\text { amputation/ } \\
\text { persistent } \\
\text { osteomyelitis/ } \\
\text { died }\end{array}$ & $\begin{array}{l}\text { Significance } \\
\text { score }^{a}\end{array}$ \\
& 42,77 & $\begin{array}{l}56,74,78, \\
81,86,86\end{array}$ & N/a \\
Age (y) & $2 / 2$ & $4 / 6$ & 1.00 \\
Male sex & $2 / 2$ & $3 / 6$ & 1.00 \\
BMl >25 kg/m² & $1 / 2$ & $0 / 6$ & 0.25 \\
$\begin{array}{l}\text { Type 1 diabetes } \\
\text { Duration of diabetes }\end{array}$ & $1 / 2$ & $4 / 6$ & 1.00 \\
$\geq 10$ years & $1 / 2$ & $1 / 6$ & 1.00 \\
$\begin{array}{l}\text { HbA1c } \geq 70 \text { mmol/mol } \\
\text { (8.6\%) }\end{array}$ & & $1 / 6$ & 1.00 \\
Peripheral vascular disease & $0 / 2$ & $6 / 6$ & 1.00 \\
Peripheral neuropathy & $2 / 2$ & $2 / 6$ & 1.00 \\
Chronic kidney disease & $1 / 2$ & & \\
Stage 4-5 & & &
\end{tabular}

ing or major amputation (rates of healing OM 2/6 [33\%]; UO $16 / 17[94 \%])$.

\section{Discussion}

This retrospective review of diabetic heel ulcer patients with and without calcaneal osteomyelitis confirms the severity of calcaneal osteomyelitis in patients with diabetes and the associated poor prognosis. Peripheral neuropathy and male gender were the principal patient factors associated with calcaneal osteomyelitis. This was surprising as it was thought that other factors including age, presence of peripheral vascular disease, obesity and poor diabetes control might be more influential. However this was only a small case series which limits interpretation of the findings.

Loss of protective sensation is an important factor in converting a superficial ulcer into a deep wound penetrating to bone. Effective offloading is vital to ulcer healing, but severe neuropathy can make this difficult to achieve, especially in a weightbearing area such as the heel; consequently superficial ulcers frequently deteriorate. ${ }^{4}$ It is possible that peripheral vascular disease was not as prevalent as anticipated due to the known distal predominance of small vessel peripheral vascular disease in people with diabetes, or perhaps patients with severe ischaemia are less mobile and therefore less likely to develop heel ulcers.

Not all patients with calcaneal osteomyelitis had presenting ulcers that probed to bone. Equally some patients without osteomyelitis presented with larger ulcers. Similarly, plain foot $\mathrm{X}$-ray changes and raised inflammatory markers were patchy at initial presentation. Nevertheless, our findings overall complement those identified in a systematic review and meta-analysis of diabetic foot infections which suggests that factors increasing the likelihood of osteomyelitis are probing to bone, ulcer size 


\section{Key messages}

- Calcaneal osteomyelitis is an uncommon type of foot infection

- Calcaneal osteomyelitis was found most often in men with diabetic neuropathy and large deep heel ulcers

- Long-term prognosis in calcaneal osteomyelitis is poor

$>2 \mathrm{~cm}^{2}$, ulcer duration $>2$ weeks or erythrocyte sedimentation rate $>70 . .^{5-8}$ Some case series suggest that a negative probe to bone test has a strong negative predictive value (0.98), whereas a positive probe to bone test only has a positive predictive value of $0.57 .{ }^{9}$ In our series, however, the inability to probe to bone did not reliably exclude osteomyelitis, consistent with many studies that suggest no single factor can reliably include/ exclude osteomyelitis. .-7 $^{-1}$

A limitation of this small case series review is that bone biopsy was not performed for microbiological identification. Other studies of diabetic foot infection have found that bone biopsy guided antibiotic treatment may be more effective. ${ }^{10}$ Additionally this is a small case series, albeit of an uncommon diabetic complication, which is bound to limit generalised interpretation of some of the findings.

This series confirms the poor prognosis associated with established calcaneal osteomyelitis. Our findings suggest that efforts for improvement should be directed primarily towards better prevention (e.g. better offloading of heel pressure in men with severe diabetic neuropathy). Perhaps bone biopsy with culture to allow targeted antibiotic therapy or early bone debridement should also be considered for such patients; particularly given the impact of reduced mobility on patients' quality of life and its probable contribution, combined with chronic inflammation, to the high mortality rates seen.

\section{Conclusion}

Calcaneal osteomyelitis is an uncommon diabetic foot complication associated with large neuropathic heel ulcers and a poor prognosis. Large, collaborative studies are warranted to explore improvements in prevention and treatment.

Conflict of interest None declared.

Funding None received.

\section{References}

1. Bakker K, Schaper NC. International Working Group on Diabetic Foot Editorial Board. The development of global consensus guidelines on the management and prevention of the diabetic foot 2011. Diabetes Metab Res Rev 2012;28 Suppl 1:116. http://dx.doi.org/10.1002/dmrr.2254

2. Lipsky BA, Berendt AR, Cornia PB et al. 2012 Infectious Diseases Society of America Clinical Practice Guideline for the Diagnosis and Treatment of Diabetic Foot Infections. Clin Infect Dis 2012;54:132-73. http://dx.doi.org/10.1093/cid/cis346

3. Pickwell KM, Siersma VD, Kars M, et al. Eurodiale consortium. Diabetic foot disease: impact of ulcer location on ulcer healing. Diabetes Metab Res Rev 2013;29:377-83. http://dx.doi.org/10.1002/dmrr.2400

4. Millington JT, Norris TW. Effective treatment strategies for diabetic foot wounds. J Fam Pract 2000;49(11 Suppl):S40-8.

5. Butalia S, Palda VA, Sargeant RJ, et al. Does this patient with diabetes have osteomyelitis of the lower extremity? JAMA 2008;299:806. http://dx.doi.org/10.1001/jama.299.7.806

6. Lavery LA, Peters EJG, Armstrong DG, et al. Risk factors for developing osteomyelitis in patients with diabetic foot wounds. Diabetes Res Clin Pract 2009;83:347-52. http://dx.doi.org/10.1016/j.diabres.2008.11.030

7. Dinh MT, Abad CL, Safdar N. Diagnostic accuracy of the physical examination and imaging tests for osteomyelitis underlying diabetic foot ulcers: meta-analysis. Clin Infect Dis 2008;47:519. http://dx.doi.org/10.1086/590011

8. Newman LG, Waller J, Palestro CJ, et al. Unsuspected osteomyelitis in diabetic foot ulcers. Diagnosis and monitoring by leukocyte scanning with indium in 111 oxyquinoline. JAMA 1991;266:1246-51. http://dx.doi.org/10.1001/jama.1991.03470090080036

9. Lavery LA, Armstrong DG, Peters EJ, et al. Probe-to-bone test for diagnosing diabetic foot osteomyelitis: reliable or relic? Diabetes Care 2007:30:270-4. http://dx.doi.org/10.2337/dc06-1572

10. Lipsky BA, Peters EJ, Senneville E, et al. Expert opinion on the management of infections in the diabetic foot. Diabetes Metab Res Rev 2012; 28 Suppl 1:163. http://dx.doi.org/10.1002/dmrr.2248 